\title{
MULHERES MONSTRUOSAS: O CTÔNICO E 0 SELVAGEM EM CARMILLA, DE LE FANU
}

Marina Pereira Penteado (FURG)

Recebido em 17 mar 2019. Marina Pereira Penteado é Doutora em Literatura Aprovado em 24 mai 2019. Comparada pela Universidade Federal Fluminense e Professora Substituta do Instituto de Letras e Artes da Universidade Federal do Rio Grande

Resumo: O presente trabalho propõe uma discussão a respeito da representação demoníaca das mulheres, através de aspectos que são normalmente ligados ao próprio feminino, na novela Carmilla: a vampira de Karnstein, de Sheridan Le Fanu. Com base em estudos que analisam a perda da autonomia da mulher sobre seu próprio corpo, o primitivo e animalesco e suas representações na literatura, além de estudos que debatem a monstruosidade percebida na figura da mulher e em quase tudo que é ligado ao feminino, busco fazer uma reflexão sobre como a incorporação do selvagem, do ctônico e do dionisíaco tomam forma em Carmilla, e até que medida esses aspectos são utilizados para justificar a morte da vampira.

Palavras-chave: Vampiros; Natureza ctônica; Mulheres monstruosas.

Abstract: This article proposes a discussion on the daemonic representation of women, through aspects generally associated with the feminine itself, in Carmilla, by Sheridan Le Fanu. Taking into account 
studies that analyze women's loss of autonomy over their own bodies, the primitive and animalistic representations in literature, as well as studies that discuss the monstrosity perceived in women and in everything connected to the feminine, I aim to analyze how the incorporation of the wild, the chthonian and the Dionysian take place in Carmilla, and to what extend this aspects are used to justify the persecution and death of the vampire.

Keywords: Vampires; Chthonian nature; Monstrous women.

Ao lado de "O vampiro" (1819), de John Polidori, e Varney the Vampyre: or the Feast of Blood (1840), de James Malcolm Rymer, Carmilla - a vampira de Karnstein, do irlandês Sheridan Le Fanu, é uma das primeiras histórias de vampiros escritas em língua inglesa. Publicada em formato de folhetim entre 1871 e 1872, além de ter exercido uma influência direta na ficção de Bram Stoker e no desenvolvimento do mito moderno do vampiro, Carmilla ainda instiga debates sobre a representação demoníaca da mulher na era Vitoriana e se mantém como uma referência literária importante para estudos que lidam com as relações entre mulheres e o feminino monstruoso. Assim, neste trabalho, proponho uma análise dessas questões através da discussão sobre o medo do ctônico, do dionisíaco e do selvagem percebidos na figura da vampira que dá nome a história, que precisa ser destruída a qualquer custo - e de preferência pelo sexo masculino -, a fim de reestruturar a ordem que a narrativa Vitoriana exige.

Escrito pouco mais de cinquenta anos antes de Carmilla, o poema "Christabel" (1816), de Samuel Taylor Coleridge, apresenta uma história parecida, na qual uma mulher, Geraldine, após escapar 
de homens que a haviam raptado, encontra Christabel, que a recebe em seu castelo. Embora Geraldine não seja chamada de vampira -e muito menos de uma vampira lésbica - na narrativa, ela claramente assume tal papel, e é representada, como Camille Paglia (1991) observa, como uma força demoníaca da natureza, aspecto que é, em certa medida, recuperado por Le Fanu. "Christabel" traz a mulher como um perigo, como um agente disruptivo do mundo apolíneo de ordem dos homens, uma vez que nele tudo que é relacionado ao feminino é perigoso.

Paglia, em seu estudo Personas Sexuais (1991), chama atenção para o fato de Coleridge ver "o horror ctônico na natureza" ${ }^{1}$, criando Geraldine como um demônio de tal natureza. Para a autora, "Christabel", seguindo o molde de outros escritos anteriores de Coleridge, parece deixar de fora a ortodoxia cristã e se infiltrar no submundo da cultura ocidental e sua mistura pagã de hermetismo, alquimia e astrologia. A incompletude do poema, para Paglia, está justamente ligada ao fato de Coleridge se aproximar da natureza e do pictorialismo pagão enquanto se afasta da ortodoxia cristã. Desta forma, a autora conclui que "Coleridge não poderia transformar sua saga demoníaca em uma parábola de redenção cristã"2 (PAGLIA, 1991, p.340), em vez disso, ele retorna a psique para um mundo primitivo e maligno na incompletude de seu poema.

Embora também com uma ideia de natureza como algo implacável, Le Fanu, por sua vez, tenta amenizar o maligno em Carmilla. Onde a heterossexualidade e a masculinidade parecem

1 "Geraldine, the green snake who strangles the dove, is the deamon of chthonian nature, trampling man in her triumph of the will." (PAGLIA, 1991, p.326)

2 "Coleridge could not turn his daemonic saga into a parable of Christian redemption." (Tradução minha). 
falhar em Coleridge, em Le Fanu elas recebem força, em uma tentativa de destruir o primitivismo que uma força demoníaca da natureza poderia causar. Com a adolescente Laura como narradora, a novela é ambientada em um castelo na Estíria, no qual Laura vive com seu pai, um inglês aposentado do exército austríaco e desatento em relação a sua filha e a nova hóspede. A história de Laura inicia com a lembrança de um sonho sobre a aparição da figura de uma bela jovem (Carmilla) em seu quarto, que a deixa com um susto e a sensação de "que duas agulhas haviam sido enfiadas" em seu peito (LE FANU, 2010, p.42). A partir de então, a narrativa se desenrola como um bom romance Vitoriano, baseada em provas e na ciência para tentar explicar eventos que pareceriam bastante duvidosos, caso não houvesse uma cópia do relatório da Comissão Imperial com os testemunhos de todos os homens envolvidos na morte da vampira para comprovar o ocorrido ${ }^{3}$.

Escrito em um período no qual a homossexualidade era considerada crime, a narrativa de Le Fanu, embora exija uma punição para os aspectos não aceitos pela sociedade Vitoriana, se destaca por ser a primeira narrativa sobre vampiras lésbicas. A natureza demoníaca que Paglia observa em Coleridge, também surge em Carmilla, causando uma tensão entre a dualidade apolínea e a dionisíaca representada, de um lado, pelos ingleses e, de outro, pela vampira estrangeira e lésbica. Com cenas de adoração e sentimentalismo entre as protagonistas, nas quais a vampira é quem quase sempre se declara, expressando sentimentos tais como "jamais me apaixonei por quem quer que seja, e jamais me

3 "Meu pai possui uma cópia do relatório da Comissão Imperial, com assinatura de todos os que presenciaram os ritos, atestando a veracidade dos depoimentos." (LE FANU, 2010, p.140) 
apaixonarei [...] a menos que seja por ti" (LE FANU, 2010, p.82), Laura parece mais contida, ainda presa ao mundo apolíneo, embora se mostre não tão ingênua quanto seria de se supor. A narradora declara se sentir "atraída por ela [Carmilla]", mas com "uma certa repulsa" (LE FANU, 2010, p.62), percebendo as aproximações de Carmilla, muitas vezes, como "estranhos acessos de adoração" (LE FANU, 2010, p.93), no que parece uma hesitação entre seguir seus impulsos, ouvir sua intuição - que avisa ter algo de estranho na situação -, ou agir com decoro.

O aspecto homossexual da obra é percebido por vários críticos como havendo sido, possivelmente, também influenciado pela história da Condessa Elizabeth Báthory de Ecsed (1560 - 1614), húngara que matou cerca de seiscentas jovens com o intuito de usar o sangue dessas mulheres para preservar sua beleza. Carmilla incorpora a monstruosidade da "condessa de sangue", que além de matar jovens moças, ainda apresentava traços homossexuais, como os sugeridos pelos relatos nos quais eram registradas cenas tais como "a condessa mordendo a carne das jovens, a colocação dos corpos semimortos das moças nuas e ensanguentadas dentro de uma banheira na qual Báthory se banhava" (SILVA, 2010 p.31), entre outras. Monstruosidade essa, também encontrada em figuras muito mais primitivas e anteriores, que foram importantes para a construção do mito do vampiro e, mais especificamente, da mulher como vampira.

Se a capacidade de gestação fez com que a mulher fosse muito mais associada à natureza do que o homem, os aspectos misteriosos, selvagens e demoníacos da natureza também foram muito mais relacionados a ela. Como Alexander Meireles da Silva 
comenta, na introdução da edição brasileira da obra de Le Fanu, no processo de associação da mulher à natureza, "o homem se definiu como racional e apolíneo, e a mulher como irracional, instintiva, ligada ao inconsciente, ao sonho e à Lua." (2010, p.18). Com uma ligação com a vida e a morte, simbolizada pela própria menstruação, a figura da mulher acabou sendo relacionada à destruição e a criação, alimentando as primeiras representações de vampiros. De Lilith, mãe dos demônios, passando por Lamia, Strix, Langsuyar, Tlahuelpuchi e a deusa hindu Kali, o ponto em comum dessas narrativas de mulheres que sugam o sangue de crianças assim como Carmilla, que se alimenta de jovens meninas - parece ser a maternidade e essa subversão do papel da mãe, em que a mesma que deu vida, termina por destruí-la de alguma forma.

Esse ciclo de vida e morte, tão ligado às próprias fases lunares, é o ponto de partida, tanto do poema de Coleridge, no qual "A lua está atrás, e está cheia”4 ( 2009, p.68) quando Geraldine surge, quanto na novela de Le Fanu. Embora quase todas as histórias de vampiros recuperem a imagem da lua em algum momento, em Carmilla, ela parece ter um significado específico interessante. A chegada da carruagem que traz a hospede é precedida pela fala de Mademoiselle De Lafontaine, uma das governantas de Laura, que repassa seu conhecimento sobre a lua e suas influências da seguinte maneira:

O efeito da lua cheia, com todo aquele brilho, era múltiplo. Atuava sobre os sonhos, atuava sobre a loucura, atuava sobre os aflitos; exercia influências físicas fantásticas sobre a vida. [...] Esta noite a lua ela dizia - está plena de força odílica e magnética...

4 "The moon is behind, and at the full." (Tradução minha) 
e veja, atrás da senhora, todas as janelas do schloss brilham e cintilam com esse esplendor prateado, como se mãos invisíveis houvessem acendido luzes nos quartos, para receber convidados feéricos. (LE FANU, 2010, p.49)

Normalmente relacionada aos aspectos de força, potência, nutrição e criação, além de ser associada, na maior parte das culturas, ao feminino, a lua cheia que provoca ações intensas na natureza, em Le Fanu, parece enfatizar um efeito dual. Ao mesmo tempo em que a luminosidade seduz, ela também amedronta com sua natureza "magnética". Tal aspecto é possível de ser observado em outras cenas, como quando Laura fala sobre a beleza de Carmilla ser realçada com a luz da lua cheia ${ }^{5}$, dando uma ideia de uma espécie de feitiço, por exemplo. Na narrativa, é no momento no qual o disco lunar está visível à noite e completamente iluminado que a chegada da carruagem de Carmilla também acontece. A força lunar e sua energia "feérica", advertida pela supersticiosa Mademoiselle De Lafontaine, além de iluminar o acidente, quando os cavalos caem ao avistar uma velha cruz de pedra à beira da estrada, fascinam quem está assistindo a cena.

Com a culpa do acidente recaindo no símbolo cristão, e não na lua, a novela narra a primeira tentativa de proteção que a família de Laura recebe contra forças supostamente demoníacas que adentravam seu território, delimitando a partir daquele momento que essa proteção vem da religião. A ameaça, que não é apenas estrangeira, mas vem também da mulher, é iluminada por um dos maiores símbolos feminino e marca a chegada de três figuras que precisam ser destacadas. Assim como a figura arquetípica da Deusa Tríplice Lunar e suas três faces:

5 Laura exclama: “Como era bela ao luar!” (LE FANU, 2010, p.82) 
donzela, mãe e anciã - todas vinculadas ao inconsciente feminino -, a novela traz Carmilla, a mãe e uma mulher negra. A escolha da lua, de uma fase lunar específica e da personagem que será central na cena reforçam a importância do símbolo utilizado. Em relação às três fases citadas, temos na novela: Carmilla, a donzela quase desmaiada; a mãe, "uma mulher vistosa, considerando a idade [...] pálida [...] com fisionomia altiva e autoritária" (LE FANU, 2010, p.51-52), que é quem conduz a conversa com os habitantes do castelo; e uma mulher que parece controlar a cena,

negra, de aspecto assustador, portando uma espécie de turbante colorido, observando o tempo todo da janela da carruagem, sacudindo a cabeça e rindo e zombando da situação, com um olhar brilhante e arregalado, os dentes cerrados (LE FANU, 2010, p.57).

Das três figuras, acompanhadas de lacaios e cavaleiros que inspiram pouca curiosidade na narrativa, apenas duas são notadas por todos os personagens: a mãe - que também é arquétipo predominante da fase da lua cheia - e a filha, que pouco interage, pois estava "aparentemente sem vida" (LE FANU, 2010, p.51). A mulher negra, por sua vez, só é percebida por Mademoiselle De Lafontaine. A figura arquetípica da anciã, normalmente ligada à cor preta e descrita como sendo alguém que supervisiona e cuida as outras duas figuras, mantendo o equilíbrio, igualmente "pode parecer terrível, uma vez que ela é o portal para morte. No entanto, ela pode ser vista também como o psicopompo que guia e indica o caminho para a nova vida"6 (FARRAR, 2012, Ed. Kindle).

6 "[she] can seem terrible, because she is the gateway to Death. But she is also the Psychopompos who guides us through it, pointing the way to the new life." (Tradução minha) 
A figura da mulher negra, de fato, proporciona a ideia de que, além dela possivelmente também ser uma vampira - e talvez a mais macabra e antiga das três -, ela ainda pode ser uma espécie de guia. Ao estar oculta sob a luz da lua cheia, reforçando a referência arquetípica da figura que ela representa, a personagem ainda aponta para questões coloniais bastante presentes, em geral, na literatura Vitoriana, e que, por sua vez, também costumam trazer tal figura para representar o monstruoso da história. No caso da narrativa de Le Fanu, essa mulher parece incorporar todo o ctônico, como uma espécie de força da natureza primitiva e selvagem, além de representar uma das faces de Carmilla, a donzela que chega ao shloss desmaiada e que em um dos seus acessos de adoração com Laura exclama "meu coração selvagem sangra" (LE FANU, 2010, p.67 - Grifo da autora).

O fato de os demais personagens não notarem haver outra figura dentro da carruagem, muito menos se questionarem sobre a situação esquisita envolvendo uma mãe que não concede sua identidade, de onde vem ou para onde vai, e que deixa a filha por três meses aos cuidados de estranhos por estar com pressa para um compromisso, é associada, possivelmente, a alguma espécie de magia ancestral na narrativa, despertada pela lua. Mademoiselle De Lafontaine, a única personagem que se permite acreditar em fantasmas e superstições, é também a única que percebe a face monstruosa de dentro da carruagem. No entanto, em sua ingenuidade, ela presta mais atenção na beleza de Carmilla do que na figura assustadora. Ao dizer "é simplesmente linda" (LE FANU, 2010, p.37) ao se referir à garota, é como se a esquisitice dos acontecimentos fosse obliterada pela beleza da jovem, sugerindo 
que talvez se Carmilla parecesse menos bonita, o perigo teria sido mais óbvio. Desta forma, como se todos estivesse sob algum feitiço, a presença da figura negra sugere que o que está prestes a acontecer não é nada natural, mas que, ao mesmo tempo, só pode vir da natureza.

Isolada do mundo e na ausência da figura materna, Laura não possui vínculos com figuras femininas fortes, embora deseje, como é possível observar pela insistência para que seu pai aceite Carmilla em seu castelo, e mesmo anteriormente, em sua frustração por saber que a sobrinha do general Spielsdorf havia cancelado a visita que ela esperava há meses. Apenas com a companhia do pai e de duas governantas, a narradora percebe na chegada da jovem a possibilidade de desenvolver uma relação mais íntima com alguém. O que Laura narra, a partir da chegada da vampira, por sua vez, longe dos olhares adultos e supervisionais dos outros integrantes do schloss, é um dos pontos fortes da história de Le Fanu, que se destaca por criar um universo só das duas personagens, no qual Carmilla, uma criatura que parece, a princípio, livre das amarras patriarcais da sociedade Vitoriana, concede um pouco da mesma liberdade à narradora, que a recebe com um misto de encanto e receio.

Se normalmente as personagens mulheres eram controladas por homens nas narrativas de vampiros, nas quais eles agiam como seus mestres, em Le Fanu, caso Carmilla responda a alguém, é provavelmente à sua mãe ou à mulher negra misteriosa da narrativa. Como Nina Auerbach observa em seu estudo Our Vampires, Ourselves (1995), "Carmilla não é produto de algum mestre, mas o espírito de uma comunidade feminina dúbia que pode ser quem a criou ou 
pode apenas ser composta por suas aliadas, mas que tem um poder percebido apenas pelas mulheres"7 (AUERBACH, 1995, p.40).

As três figuras, além de interagirem de uma maneira singular entre si, ainda parecem compartilhar da natureza ctônica que irá ameaçar a ordem Vitoriana. Desta forma, as características demoníacas que Mademoiselle De Lafontaine nota na mulher negra também estão em Carmilla e na figura da mãe, embora camufladas em uma aparência mais cativante. Laura nota que "havia algo de distinto e mesmo imponente no semblante e na aparência daquela dama" (LE FANU, 2010, p.53), ao se referir a mãe de Carmilla, sugerindo haver na magnitude específica da personagem algo ancestral e feminino que não parece fazer parte daquele universo Vitoriano racional.

Ainda sobre a figura negra, Auerbach a percebe como "o próprio diabo na forma de uma sacerdotisa voodoo; suas associações exóticas, raciais e espirituais, insinuam uma magia feminina que ultrapassa a extensão geográfica oriental e dominantemente masculina de Byron ou a tradição nórdica de Varney"8 (AUERBACH, 1995, p.40). A mulher de aspecto assustador, que parece uma espécie de Baba Yaga das vampiras - alguém que está ali para aconselhar as duas mais jovens é sem dúvida uma força implacável, ctônica. Tal aspecto também é percebido por Claude Lecouteux, que identifica Carmilla como uma narrativa que se insere "em uma longa linhagem de crenças e tradições que remonta às bruxas e magas da Antiguidade clássica" (2003, p.21), reforçando esse aspecto do

7 "Carmilla is not the product of a single maker's potency, but the spirit of an elusive female community who may be her makers or merely her condeferates, and whose power only women perceive." (Tradução minha)

8 "the devil herself in the form of a voodoo priestess; her exotic associations, racial and spiritual, hint at a geographic range of female magic beyond Byron's male-ruled Orient or Varney's Nordic lore". (Tradução minha) 
feminino demoníaco na obra. O que a personagem negra sugere, no final, é que ela é o lado mais selvagem, estritamente ligado à natureza das mulheres, aquele que sai à noite e suga o sangue das moças camponesas sem que ninguém veja.

Além de nenhuma figura mais velha e autoritária retornar para controlar Carmilla na novela, as personagens femininas ainda parecem se unir de uma maneira que os homens que as observam não conseguem perceber, ou penetrar, como Auerbach nota ${ }^{9}$, tornando-as ainda mais demoníacas. Carmilla invade o castelo do pai de Laura e o tira da posição de poder e dominação, criando uma narrativa que pertence apenas às mulheres, e mais especificamente a ela e Laura. A ausência de nome do pai da narradora já é significativa, uma vez que ele é uma das figuras centrais da novela e que aparece do início ao fim. Sempre sendo referido como "pai", enquanto até a mãe morta de Laura recebe uma identidade mais consistente - sabemos que ela é descendente dos Karnstein, mesma família de Carmilla -, apenas sabemos que ele é inglês.

Carmilla não faz de Laura apenas sua presa, mas estabelece uma relação mais intensa, que passa completamente despercebida pelo pai e pelos os outros integrantes do schloss. Sua relação com Laura não é apenas para saciar seus desejos, para isso, ela se alimenta de garotas camponesas da região. Em Laura, alguém da mesma classe social sua, a vampira se identifica de uma maneira mais profunda e permite que sua amante sobreviva por muito mais tempo que as outras vítimas. No entanto, da mesma forma que a construção das duas personagens se destaca por elas serem criadas em um espaço impenetrável - a princípio

9 "(...) women in Carmilla merge into a union the men who watch them never see." (AUERBACH, 1995, p.43) 
- pelo masculino, ambas também são dividas em opostos, como já citado: Laura, a apolínea, e Carmilla, a dionisíaca. Tal divisão, que justifica a destruição do lado monstruoso, é pautada na cientificidade dos homens da narrativa, que explicam até mesmo o comportamento de cortejo de Carmilla como sendo algo comum em alguns vampiros ${ }^{10}$, de forma a neutralizar a atração entre as duas personagens.

A tentativa de explicar racionalmente todos os acontecimentos, dos relatos dos médicos às citações de livros, entra em conflito com tudo que a vampira parece trazer à narrativa. A insuficiência da ciência e da racionalidade para explicar o desaparecimento de Carmilla dentro do castelo no final da novela é um exemplo. Após diversas conjecturas sobre o ocorrido, o pai de Laura chega a uma conclusão bastante falha de que só pode ser o sonambulismo que fez a garota desaparecer de seu quarto, conclusão da qual ele ainda se vangloria ao dizer "devemos nos felicitar, porque a explicação mais natural do ocorrido não implica entorpecente, arrombamento de fechadura, ladrão, veneno, ou bruxas... nada que possa assustar Carmilla, ou qualquer um de nós" (LE FANU, 2010, p.101). É o alívio de criar uma explicação racional para não precisar lidar com o que existe de não compreensível e assustador na natureza de Carmilla, mesmo que a explicação faça pouco sentido.

A vampira traz o indomável da natureza, se apresentando como uma força perversa e feroz, ao mesmo tempo em que também é

10 "O vampiro tendo a se fascinar por determinadas pessoas, com grande ardor, algo similar à paixão carnal. Nesses casos o vampiro demonstra paciência e ardis inesgotáveis, visto que o acesso ao objeto desejado, por vezes, apresenta uma centena de obstáculos. O vampiro não descansa enquanto não sacia a paixão e drena a vida da vítima cobiçada. Mas, ao mesmo tempo, sabe guardar e postergar o prazer assassino, com o refinamento de um epicurista, intensificando tal prazer por meio de abordagens sutis que caracterizam o amor cortês." (LE FANU, 2010, p.143-144) 
maternal. Tal força, a princípio, é explicada como inabalável, como quando Carmilla zomba dos amuletos de proteção compostos por longas tiras de pergaminho, contendo códigos e diagramas cabalísticos, comprados por ela e Laura de um andarilho. Ela pergunta: "[...] você acredita que espíritos do mal se assustam com pedacinhos de fita, ou com perfumes criados no laboratório de um químico?" (LE FANU, 2010, p.92). O que ela deixa explícito é que sua força, que como a de Geraldine é demoníaca e de natureza ctônica, não pode ser diminuída ou destruída pelos homens e seus esforços em criar medidas apotropaicas para impedir a natureza de se manifestar.

Carmilla, dessa forma, tenta expor o poder que existe em tudo que é selvagem e que vem da natureza. Em um diálogo com o pai de Laura sobre a praga que assola a região onde eles estão, tal característica pode ser observada novamente. Enquanto a figura masculina da narrativa prega sobre como Deus irá salvá-los do que quer que esteja acontecendo, Carmilla questiona o poder do Deus cristão e indica que o que está acontecendo é algo mais primitivo e forte, é algo que não pode ser controlado:

Criador! Natureza! - disse a jovem, respondendo ao meu amável pai. - E esta praga que assola a região é natural. Natureza. Tudo vem da Natureza... não é? Tudo o que existe no céu, na terra e embaixo da terra opera e vive segundo os comandos da Natureza? Creio que sim. (LE FANU, 2010, p.76grifos meus)

A forma felina assumida por Carmilla durante a narrativa, por sua vez, também tem a ver com essa natureza e com a força do selvagem e do primitivo que foge ao controle da sociedade Vitoriana. Como Maria Esther Maciel observa em um estudo sobre 
animalidade, "a parte animal, uma vez manifesta, despojaria o homem de sua humanidade, conduzindo-o ao grau-zero de sua própria natureza" (2016, p.17), e Carmilla precisa ser desumanizada para poder ser destruída. Todos os desejos reprimidos e o que não é aceito são personificados na personagem que assume a forma de um grande felino antes de contaminar suas vítimas. A transformação da personagem em um animal, além de desumanizar Carmilla, ainda contribui para ligá-la ao seu lado ctônico, tendo em vista que o relacionamento entre homem e animal está diretamente conectado à ideia de poderes malignos, subterrâneos e tudo que possa ser repreensível. E nada é mais repreensível que a homossexualidade que vem de fora para cooptar a filha do inglês e tirar o poder dos homens da comunidade.

Como Marcia Heloisa Amarante Gonçalves observa em sua dissertação sobre animalidade em Drácula, com as teorias de Darwin de seleção natural e de que todos os seres tem uma forma ancestral em comum, surge a ideia da existência de um parentesco diabólico, e na literatura vitoriana, "o animal-homem desponta como deformidade e é preciso reconhecê-lo, classificá-lo, segregálo o quanto antes" (2012, p.84-85). Após a confirmação da culpa de Carmilla, que vem com sua imagem em um quadro no qual se lê o nome de "Mircalla, Condessa de Karnstein", e no relato do Coronel Spielsdorf - que a reconhece como Millarca (outro anagrama), assassina de sua sobrinha -, a figura demoníaca é então reconhecida como vampira, classificada como uma Karnstein e, finalmente, mutilada, a fim de expulsar o mal da comunidade.

Ao desafiar a racionalidade do período com sua monstruosidade, Carmilla desautoriza a sociedade Vitoriana, que precisa tentar 
controlá-la e explicá-la racionalmente através da ciência, para enfim, destruí-la através da religião. A ofensa que ela oferece é grande demais, pois ela não se contenta com as garotas camponesas da região - das quais em nenhum momento alguém parte em defesa -, ela se alimenta de duas garotas da alta classe. Seu relacionamento com Laura é perigoso, uma vez que desautoriza o pai e traz o erotismo homossexual para dentro da casa dos ingleses, contaminando a pureza da filha e ameaçando o protótipo do "anjo do lar"11 - que Virginia Woolf vai dizer habitar todos os lares Vitorianos naquela época. Carmilla viola o corpo de sua vítima com mordidas e, como Gonçalves ainda observa:

O corpo invadido pelo animal - por violação o ou anomalia orgânica - é também um corpo erotizado, que representa a ansiedade vitoriana com a definição de papéis sexuais, a sombra da homossexualidade, os embrionários movimentos feministas e o temor inspirado pela miscigenação. (2012, p.86)

Nesse sentido, o contágio que Laura sofre é repleto de boa parte dos medos Vitorianos. Se com o gradual predomínio da ideologia patriarcal em detrimento de culturas matriarcais, o mito do vampiro passou a ser mais associado à transgressões das normas sociais, "fundamentadas em um pensamento cristão e, por conseguinte, masculino" (SILVA, 2010, p.24), é interessante notar que o vampiro assumiu o papel das bruxas depois do século XVIII:

110 anjo do lar é descrito por Woolf como "extremamente simpática. Imensamente encantadora. Totalmente altruísta. Excelente nas difíceis artes do convívio familiar. Sacrificava-se todos os dias. (...) em suma, seu feitio era nunca ter opinião ou vontade própria, e preferia sempre concordar com as opiniões e vontades dos outros. E acima de tudo, nem preciso dizer - ela era pura. Sua pureza era tida como sua maior beleza enrubescer era seu grande encanto. Naqueles dias - os últimos da rainha Vitórica - toda casa tinha seu Anjo." (2010, p.12) 
Há provas de que o declínio dos julgamentos de bruxaria, impostos de cima pela legislação iluminista da imperatriz M. Teresa, seguiu-se um aumento na crença de vampiros e vampirismo. Os vampiros ofereceram uma explicação sobrenatural alternativa para os infortúnios quando a bruxaria já não se encontrava mais disponível. (BAILEY, 2003, p.136)

A vampira lésbica que contamina a família nobre e católica, transgredindo as normas sociais e colocando a filha do inglês em perigo, assume um papel, de fato, semelhante ao das bruxas que eram condenadas e queimadas. Carmilla tem sua sepultura violada pelos homens respeitáveis da comunidade, seu corpo avaliado e exumado, uma estaca pontiaguda cravada em seu coração, é decepada e, finalmente, tem seu corpo reduzido a cinzas ${ }^{12}$. A narrativa imposta pela igreja católica em momentos como o da caça às bruxas, na qual as mulheres eram demonizadas e associadas a uma natureza monstruosa, em certa medida, se assemelha bastante com a da vampira.

Essa demonização das mulheres, que não é exclusiva de um período histórico específico, como bem apontado por Silvia Federici, mas parece perseguir as mulheres incansavelmente através dos séculos, foi intensificada com o estabelecimento do capitalismo. Em um estudo que aborda a caça às bruxas como havendo sido um movimento que tentava destruir o controle que as mulheres haviam adquirido sobre sua própria função reprodutiva, Federici nota que

12 "A sepultura da Condessa Mircalla foi aberta; o general e meu pai reconheceram, na face agora exposta, a bela e pérfida hóspede. (...) Os dois médicos, um ali presente, o outro representado pela pessoa do promotor público, atestaram fatos absolutamente fabulosos (...) Então, segundo a antiga prática, o corpo foi exumado e uma estaca pontiaguda foi cravada no coração da vampira (...) Em seguida, a cabeça foi decepada (...) O corpo e a cabeça foram, posteriormente, depositados sobre uma pilha de lenha e reduzidos às cinzas". (LE FANU, 2010, p.140-141) 
o capitalismo precisou destruir "a herege, a curandeira, a esposa desobediente, a mulher que ousa viver só, a mulher obeah que envenenava a comida do senhor e incitava os escravos a rebelião" (2017, p.24 - Grifo da autora) como forma de controle.

O medo que as mulheres da comunidade de Carmilla parecem proporcionar, ao se regularem sozinhas sem a figura de um mestre, tem muito a ver com a repressão que o patriarcado tentou estabelecer em relação aos corpos das mulheres. A personagem identificada como mãe da vampira, durante o baile no qual encontra o general Spielsdorf, tenta (e consegue), mais de uma vez, se desvencilhar do general que insiste para que ela remova sua máscara, em uma espécie de flerte. Com sua desobediência, ela mostra que não pode ser desestabilizada pelo homem em questão. Carmilla, por sua vez, além de seduzir, violar o corpo de Laura e estabelecer com a mesma uma relação durante a narrativa, também retira o poder do pai, que é excluído da história das duas. Assim, as vampiras de Le Fanu não inspiram apenas o medo do contágio com o estrangeiro e o medo do contágio sexual e homossexual, mas realizam uma transgressão que exclui o patriarcado, colocando-o em segundo plano. O medo de perder o lugar frente à forças femininas é um dos mais presentes na narrativa, da mesma maneira que foi na caça às bruxas e mesmo anteriormente, na perseguição dos hereges, que condenou e matou um número enorme de mulheres, muito mais do que em qualquer outro momento histórico anterior. Para Federici:

Desde tempos muito antigos (depois que o cristianismo se tornou a religião estatal no século IV), o clero reconheceu o poder que o desejo sexual conferia às mulheres sobre os homens $e$ tentou persistentemente exorcizá-lo, identificando 
o sagrado com a prática de evitar as mulheres e o sexo. Expulsar as mulheres de qualquer momento da liturgia e do ministério dos sacramentos; tentar roubar os poderes mágicos das mulheres de dar vida ao adotar trajes femininos; e fazer da sexualidade um objeto de vergonha - esses foram os meios pelos quais uma casta patriarcal tentou quebrar o poder das mulheres e de sua atração erótica. $(2017$, p.80)

Embora as tentativas de controlar os corpos das mulheres, como Federici nota, venham junto com o cristianismo, as narrativas que seguiram com o desenvolvimento do capitalismo silenciaram cada vez mais a sexualidade feminina, primeiro chamando-as de bruxas, para depois demonizá-las como vampiras ou qualquer outro monstro que viesse suprir a necessidade de cada época específica. O medo do desejo sexual das mulheres e, mais, o receio delas não precisarem dos homens, assusta. Por isso, quando as mulheres conseguem estabelecer um grupo fechado, no qual os homens não conseguem penetrar, a ordem Vitoriana é ameaçada em Le Fanu. O medo do feminino e de tudo aquilo que possa ser relacionado a ele, desde os ciclos menstruais - que, por sua vez, são ligados às fases lunares - até a maternidade, acabam expondo, em Carmilla, boa parte das ansiedades Vitorianas.

A vampira de Karnstein, em última análise, ameaça o patriarcado. Como Barbara Creed vai notar, "como com todos os estereótipos do feminino [o monstro feminino] é definido em relação a sua sexualidade"13 $(1993$, p.3), e Carmilla assume essa natureza demoníaca por seu poder sexual - e homossexual -,

13 "as with all other stereotypes of the feminine [the female monster] is defined in terms of her sexuality". (Tradução minha) 
mostrando sua soberania ao não depender de figuras masculinas nem ser dominada por elas.

Assim, enquanto a narrativa recupera a natureza ctônica de Coleridge para construir a vampira protagonista - em uma constante luta de poderes entre natureza e ciência -, ela desafia a ordem apolínea da sociedade, invocando o horror Vitoriano da perda de autonomia masculina para algo que não pode nem mesmo ser explicado racionalmente, algo que é identificado na novela como tendo uma origem mais primitiva, selvagem e, também, feminina. Carmilla: a vampira de Karnstein subverte o papel social da mulher na literatura Vitoriana com sua homossexualidade, com o ataque à maternidade e com a ameaça às próximas gerações. No entanto, a destruição de Carmilla pelos homens da narrativa, com toda uma violência contra seu corpo, marca a impossibilidade de completar o ato de transgressão, bem como a necessidade Vitoriana de punir tal tentativa de subversão de papel. A presença de uma vampira lésbica que ataca diretamente o patriarcado e o poder masculino não poderia ter outro fim. Talvez nem nos dias de hoje.

\section{REFERÊNCIAS}

AUERBACH, Nina (1995). Our Vampires, Ourselves. Chicago: University of Chicago Press.

BAILEY, Michael D (2003). Historical Dictionary of Witchcraft. Lanham, Maryland, and Oxford: The Scarecrow Press.

COLERIDGE, Samuel Taylor (2009). "Christabel". In: COLERIDGE, Samuel Taylor. The Major Works. Oxford: Oxford University Press.

CREED, Barbara (1993). The Monstrous Feminine: Film, Feminism, Psychoanalysis. USA: Routledge. 
FARRAR, Janet e Stewart (2012). The Witches' Goddess: The Feminine Principle of Divinity. USA: David \& Charles Edição Kindle.

FEDERICI, Silvia (2017). Calibã e a bruxa: mulheres, corpo e acumulação primitiva. São Paulo: Elefante.

GONÇALVES, Marcia Heloisa Amarante (2012). Animalidade confundida: vilania e monstruosidade em Drácula. (Dissertação). Universidade Federal Fluminense, Niterói.

LECOUTEUX, Claude (2003). História dos vampiros: autópsia de um mito. São Paulo: Unesp.

LE FANU, Sheridan (2010). Carmilla: a vampira de Karnstein. São Paulo: Hedra.

MACIEL, Maria Esther (2016). Literatura e animalidade. São Paulo: Civilização Brasileira.

PAGLIA, Camille (1991). Sexual Personae: Art and Decadence from Nefertiti to Emily Dickinson. New York: Vitage Books.

SILVA, Alexandre Meireles da (2010). "Introdução". In: LE FANU, Sheridan. Carmilla: a vampira de Karnstein. São Paulo: Hedra.

WOOLF, Virginia (2012). Profissão para mulheres e outros artigos feministas. Porto Alegre: L\&PM Pocket. 